\title{
Moderate alcohol consumption increases cholesterol efflux mediated by ABCA1
}

\author{
J. W. J. Beulens, ${ }^{*, \dagger}$ A. Sierksma, ${ }^{*}$ A. van Tol, ${ }^{\S}$ N. Fournier, ${ }^{* *}$ T. van Gent, ${ }^{\S}$ J-L. Paul, ${ }^{* *}$ \\ and H. F. J. Hendriks ${ }^{1, *}$ \\ Netherlands Organization for Applied Scientific Research (TNO), Nutrition and Food Research, ${ }^{*}$ Zeist, \\ The Netherlands; Wageningen University, ${ }^{\dagger}$ Wageningen, The Netherlands; Departments of Biochemistry and \\ Cell Biology \& Genetics, ${ }^{\S}$ Erasmus University Medical Center, Rotterdam, The Netherlands; and Laboratoire \\ de Biochimie,** Faculté des Sciences Pharmaceutiques, Châtenay-Malabry, France
}

\begin{abstract}
Moderate alcohol consumption increases HDL cholesterol, which is involved in reverse cholesterol transport (RCT). The aim of this study was to investigate the effect of moderate alcohol consumption on cholesterol efflux, using J774 mouse macrophages and Fu5AH cells, and on other parameters in the RCT pathway. Twenty-three healthy men (45-65 years) participated in a randomized, partially diet-controlled, crossover trial. They consumed four glasses of whisky (40 $\mathrm{g}$ of alcohol) or water daily for 17 days. After 17 days of whisky consumption, serum capacity to induce ABCA1-dependent cholesterol efflux from J774 mouse macrophages was increased by $17.5 \%(P=0.027)$ compared with water consumption. Plasma capacity to induce cholesterol efflux from Fu5AH cells increased by $4.6 \%$ $(P=0.002)$. Pre $\beta-H D L$, apolipoprotein A-I (apoA-I $)$, and lipoprotein A-I:A-II also increased by 31.6, 6.2, and $5.7 \%$ $(P<0.05)$, respectively, after whisky consumption compared with water consumption. Changes of cAMP-stimulated cholesterol efflux correlated $(r=0.65, P<0.05)$ with changes of apoA-I but not with changes of pre $\beta$-HDL $(r=$ $0.30, P=0.18)$. Cholesterol efflux capacities from serum of lean men were higher than those from overweight men. fir In conclusion, this study shows that moderate alcohol consumption increases the capacity of serum to induce cholesterol efflux from J774 mouse macrophages, which may be mediated by ABCA1.-Beulens, J. W. J., A. Sierksma, A. van Tol, N. Fournier, T. van Gent, J-L. Paul, and H. F. J. Hendriks. Moderate alcohol consumption increases cholesterol efflux mediated by ABCA1. J. Lipid Res. 2004. 45: 1716-1723.
\end{abstract}

Supplementary key words ATP binding cassette transporter $1 \cdot$ reverse cholesterol transport $\bullet$ J774 macrophages $\bullet$ Fu5AH cells $\bullet$ pre $\beta$ high density lipoprotein $\bullet$ body mass index

Atherosclerosis is a condition of the major arteries leading to cardiovascular disease (CVD), in which progressive occlusion of the arteries occurs by the formation of atherosclerotic lesions. A major event in this process is the

Manuscript received 18 March 2004 and in revised form 18 May 2004.

Published, JLR Papers in Press, July 1, 2004.

DOI 10.1194/jlr.M400109-JLR200 differentiation of monocytes to macrophages that accumulate lipoprotein-derived cholesterol to form "foam" cells (1).

Epidemiologic studies have shown that moderate alcohol consumption is associated with a decreased risk of CVD (2). Several mechanisms, such as a reduction in blood coagulation and fibrinolysis, may be involved in the protective effect of moderate alcohol consumption on CVD $(3,4)$. However, more than $50 \%$ of the protective action of alcohol consumption is mediated by an increase of HDL cholesterol (HDL-C) $(5,6)$. In previous studies, we have shown that moderate alcohol consumption results in an increased blood HDL-C concentration (7-9). The functional consequences of this increase in HDL-C concentration are not fully understood, but one of the protective actions may involve an increase of paraoxonase activity, an HDL-associated enzyme that may protect LDL against oxidation $(8,10,11)$.

The role of HDL in reverse cholesterol transport (RCT) is another proposed mechanism for these protective effects. RCT consists of the following steps: efflux of free cholesterol (FC) from peripheral tissue, esterification of FC by plasma LCAT, and incorporation of cholesteryl esters (CEs) in the HDL particle. HDL-CEs are cleared from plasma by the liver for catabolism via several pathways (12).

The first step in RCT, cholesterol efflux, can be mediated by three mechanisms $(13,14)$. The first mechanism is aqueous diffusion, in which cholesterol molecules desorb from the plasma membrane to be captured by acceptors such as mature HDL particles. The second mecha-

Abbreviations: apoA-I, apolipoprotein A-I; BMI, body mass index; CE, cholesteryl ester; CETP, cholesteryl ester transfer protein; CVD, cardiovascular disease; FC, free cholesterol; HDL-C, HDL cholesterol; LpA-I, lipoprotein A-I; PL, phospholipid; PLTP, phospholipid transfer protein; RCT, reverse cholesterol transport; SR-BI, scavenger receptor class B type I; TC, total cholesterol; TG, triacylglycerol.

${ }^{1}$ To whom correspondence should be addressed.

e-mail: hendriks@voeding.tno.nl 
nism of efflux involves the scavenger receptor class B type I (SR-BI). SR-BI mediates cellular cholesterol efflux to mature HDL particles in addition to its role in selective lipid uptake $(13,14)$. In one of our previous studies $(15)$, we showed that moderate alcohol consumption increased plasma capacity to induce cholesterol efflux from Fu5AH rat hepatoma cells, which have high levels of SR-BI.

The third mechanism of cholesterol efflux involves the release of FC to lipid-free or lipid-poor apolipoproteins, particularly apolipoprotein A-I (apoA-I) and pre $\beta-H D L$, which is mediated by ABCA1. This lipid efflux is the first stage of HDL biogenesis. Subsequently, FC is esterified by LCAT and mature, spherical $\alpha$-HDL particles are formed (13). Efficient cholesterol efflux from macrophages is critical for the prevention of foam cell formation, and increased cellular ABCA1 levels may thus protect against atherosclerosis (16). To the best of our knowledge, the effect of moderate alcohol consumption on cholesterol efflux mediated by the ABCA1 receptor has never been investigated. Therefore, we have used the recently validated model of ABCA1-expressing J774 macrophages (17) to study the effect of moderate alcohol intake on serum cholesterol efflux capacity.

\section{SUBJECTS AND METHODS}

\section{Subjects}

Twenty-four male subjects aged 45-65 years, all apparently healthy and nonsmoking, were recruited from the Netherlands Organization for Applied Scientific Research (TNO) BIBRA International (Carshalton, Surrey, UK) database of healthy human volunteers, by advertising in local newspapers, and by leaflet drops to local residential areas. A questionnaire (self-report) was used for information on alcohol intake, medical history, and family history of alcoholism. The questionnaire was checked by a medical investigator during an interview with the volunteer, and subsequently a physical examination was performed. Subjects were considered healthy based on the values of the prestudy laboratory tests, their medical history, and the physical examination. Subjects met the following inclusion criteria: consumption of between 10 and 28 alcohol-containing beverages weekly, body mass index (BMI) between 20 and $35 \mathrm{~kg} / \mathrm{m}^{2}$, and no family history of alcoholism. A wide range of BMIs was chosen to investigate whether the effect of moderate alcohol consumption on the outcome measures is modified by level of obesity. The study was conducted in accordance with the Declaration of Helsinki South Africa Revision 1996 and the International Conference of Harmonisation Harmonized Tripartite Guideline for Good Clinical Practice. Approval to proceed with the study was given by an independent medical ethics committee, and all subjects provided written informed consent before participation.

\section{Study design}

The subjects entered a randomized, partially diet-controlled, crossover trial consisting of two periods of 17 days. A random sample of 12 men were allocated to the sequence of consuming whisky (Famous Grouse Scotch Whisky, 40 vol\% alcohol) during dinner in the first period followed by drinking tap water (control beverage) during dinner in the second period. The other 12 men consumed water first, followed by whisky. The participants and staff administering the protocol were not blinded to the treatment sequence.

Four glasses (125 $\mathrm{ml}$ in total) of each beverage were consumed daily during dinner at TNO BIBRA. One glass was taken before dinner, two glasses during dinner, and one glass after dinner. During the whisky period, alcohol intake equaled $40 \mathrm{~g} /$ day.

The daily dinner contained $\sim 4,200 \mathrm{~kJ}$ and consisted of $\sim 21 \%$ of energy from protein, $38 \%$ of energy from fat, and $41 \%$ of energy from carbohydrate. The menu consisted of a 4-day rotation. Dinner was prepared each day by a local caterer using the same source of ingredients throughout.

Each period was preceded by 3 alcohol-free days to prevent carryover effects. Subjects were asked to continue their normal eating habits (except for the provided dinner) and carry on with their normal everyday activities. Compliance with the protocol was checked by a daily questionnaire. Body weight was measured on the first and last days of each treatment period with the subjects wearing indoor clothing, without shoes, wallet, and keys. An alcohol breath test (Alcoholtest 7410; Dräger Nederland, Zoetermeer, The Netherlands) was performed during the whisky treatment to ensure that subjects left the institute safely.

At the end of each treatment period, fasting blood samples were collected in the morning. Blood was taken from an antecubital vein and collected in a tube containing lithium-heparin to obtain plasma and in a tube containing gel and clot activator to obtain serum (Vacutainer Systems; Becton Dickinson, Plymouth, UK). To obtain plasma, the blood was centrifuged for $20 \mathrm{~min}$ at 2,000 $\mathrm{g}$ and $4^{\circ} \mathrm{C}$ between 15 and $30 \mathrm{~min}$ after collection. To obtain serum, the blood was centrifuged for $15 \mathrm{~min}$ at 2,000 $\mathrm{g}$ and $4^{\circ} \mathrm{C}$ between 15 and $30 \mathrm{~min}$ after collection. The plasma and serum samples were stored at $-80^{\circ} \mathrm{C}$ until analysis.

HDL was separated from the apoB fraction by precipitation of the latter with polyethylene glycol. Serum total and HDL-C (cholesterol oxidase/peroxidase-amidopyrine method) and triacylglycerols (TGs; glycerol phosphate oxidase/peroxidase-amidopyrine method), as well as unesterified cholesterol, TG, and phospholipids (PLs) in HDL, were analyzed enzymatically. The coefficients of variation within runs were $0.8 \%$ for total cholesterol (TC), $1.5 \%$ for TG, and $1.3 \%$ for HDL-C. CEs were calculated as the difference between HDL-FC and total HDL-C. LDL-C was calculated by the equation of Friedewald, Levy, and Fredrickson (18). ApoA-I was analyzed in serum according to a commercial nephelometric assay on the Cobas Mira S (Roche). Lipoprotein A-I (LpA-I; containing apoA-I but not apoA-II) concentrations were determined by double rocket immunoelectrophoresis using the assay kit provided by Sebia (Benelux N.V., Brussels, Belgium), according to the instructions of the manufacturer. The stained and dried gels were scanned and rocket heights were determined. A standard curve was made based on the linear relationship between rocket height and concentration. LpA-I concentration was determined as a function of rocket height, whereas LpA-I:A-II was calculated by subtraction (total plasma apoA-I minus LpA-I).

\section{Quantification of pre $\beta$-HDL by crossed immunoelectrophoresis}

The crossed immunoelectrophoresis consisted of agarose electrophoresis in the first dimension for separation of lipoproteins with pre $\beta$ and $\alpha$ mobility. Antigen migration from the first agarose gel onto the second agarose gel, containing goat anti-human apoA-I antiserum $(3 \%, \mathrm{v} / \mathrm{v})$, was used to quantitatively precipitate apoA-I. The antiserum was monospecific for human apoA-I. Lipoprotein electrophoresis was carried out on $1 \%$ (w/v) agarose gels in barbital buffer ( $50 \mathrm{mmol} / \mathrm{l}, \mathrm{pH}$ 8.6). Plasma was applied at $3 \mu \mathrm{l} /$ well and run in an LKB 2117 system $\left(4^{\circ} \mathrm{C}\right.$ for $2 \mathrm{~h}$, $250 \mathrm{~V}$ for the first dimension). The track of the first agarose gel 
was excised and annealed with melted agarose to a gel containing 3\% (v/v) goat anti-human apoA-I antiserum that was cast on GelBond film (Pharmacia). The plate was run in an LKB 2117 system $\left(4^{\circ} \mathrm{C}\right.$ for $\left.20 \mathrm{~h}, 50 \mathrm{~V}\right)$ in barbital buffer. Unreacted antibody was removed by extensive washing in phosphate-buffered saline. The gel was stained with Coomassie brilliant blue R250 and subsequently dried. Areas under the pre $\beta$-HDL and $\alpha-\mathrm{HDL}$ peaks were scanned and calculated using Scion software. The pre $\beta$-HDL area can be expressed as the percentage of the sum of the pre $\beta$-HDL and the $\alpha$-HDL areas. The pre $\beta$-HDL concentrations are given in absolute amounts (milligrams of apoA-I present in pre $\beta$-HDL per milliliter of plasma). These values were calculated from the percentage of apoA-I present in pre $\beta$-HDL and the total plasma apoA-I concentration.

\section{Plasma cholesteryl ester transfer protein, LCAT, and phospholipid transfer protein activity}

Plasma cholesteryl ester transfer protein (CETP) activity was determined after removal of VLDL and LDL from each sample as described previously $(19,20)$. The isotope assay measures the transfer of $\left[1-{ }^{14} \mathrm{C}\right.$-oleate $] \mathrm{CE}$ from labeled LDL to an excess of unlabeled normal HDL. LCAT was inhibited with dithiobis-2nitrobenzoic acid. CETP activity was calculated as the bidirectional transfer between labeled LDL and HDL. There is a strong correlation between the measured CETP activities and CETP mass (21). Plasma LCAT activity was measured using excess exogenous substrate as described (22). Plasma phospholipid transfer protein (PLTP) activity was also measured with exogenous substrates $(20)$. Plasma samples were incubated with $\left[{ }^{3} \mathrm{H}\right]$ phosphatidylcholine-labeled liposomes and an excess of HDL. Thereafter, the liposomes were precipitated with a mixture of $\mathrm{NaCl}, \mathrm{MgCl}_{2}$, and heparin (final concentrations of $230 \mathrm{mmol} / 1,92 \mathrm{mmol} / \mathrm{l}$, and $200 \mathrm{U} / \mathrm{ml}$, respectively). This method is not affected by the PL transfer-stimulating action of CETP (20). The measured CETP, LCAT, and PLTP activities are linearly related to the amount of plasma used in all incubations. The plasma CETP, LCAT, and PLTP activities obtained with these methods reflect the active amount of these proteins in plasma and are not influenced by the endogenous plasma lipoproteins.

For each assay, all plasma samples were analyzed in one run using the same batch of substrates. Plasma CETP, LCAT, and PLTP activities were related to a reference pool of human plasma obtained by mixing equal amounts of plasma, isolated at $4^{\circ} \mathrm{C}$, from 250 healthy blood donors. All activities are expressed in arbitrary units, corresponding to the percentages of the respective activities in the reference pool plasma; $100 \%$ is equivalent to the following activities: $216 \mathrm{nmol} / \mathrm{ml} / \mathrm{h}$ for CETP, $65 \mathrm{nmol} / \mathrm{ml} / \mathrm{h}$ for LCAT, and $13.9 \mu \mathrm{mol} / \mathrm{ml} / \mathrm{h}$ for PLTP. The within-assay coefficients of variation for the assays of plasma CETP, LCAT, and PLTP activities amount to $2.7,4.5$, and $3.5 \%$, respectively.

\section{Cholesterol efflux from J774 cells}

Cholesterol efflux from J774 mouse macrophage cells was determined by the use of a previously validated modification (17, 23, 24) of the general technique described by Sakr et al. (25). The current experiment is based on previous tests using normolipidemic human serum to obtain an optimal dilution for serum and was carried out strictly according to the experimental conditions described by Fournier et al. (17). Briefly, serum samples diluted to $1 \%$ were incubated at $37^{\circ} \mathrm{C}$ with the $\left[{ }^{3} \mathrm{H}\right]$ cholesterollabeled cells pretreated for $10-12 \mathrm{~h}$ with or without $0.3 \mathrm{mmol} / 1$ 8-(4-chlorophenylthio) cAMP (Sigma). To prevent intracellular cholesterol esterification, the ACAT inhibitor GW 447C88 was added into the medium during the labeling period and all subsequent stages of the experiment. After $4 \mathrm{~h}$ of incubation, the radioactivity released to the medium was expressed as the fraction of the total radioactive cholesterol present in the well. The percentage of ABCA1-mediated FC efflux was calculated as the percentage of FC efflux from cells upregulated with cAMP minus the percentage of FC efflux from control J774 cells. This calculation controls for the contribution of FC efflux from the aqueous diffusion mechanism and yields data that are specific for the contribution of ABCA1 (ABCA1-dependent cholesterol efflux). All determinations were made in triplicate. A standard pool of human serum was used to assess the daily variation in efflux experiments. The efflux values obtained with the standard pool of all experiments are averaged, and this serves as the $100 \%$ value. Each value of the experiments with the standard pool is calculated as a percentage of the overall average, and this percentage is applied to correct all test values for that day.

\section{Cholesterol efflux from Fu5AH cells}

The capacity of plasma to induce cholesterol efflux from Fu5AH cells was measured as described by de la Llera Moya, et al. (26). In short, Fu5AH cells were grown to confluency in the presence of $\left[{ }^{3} \mathrm{H}\right]$ cholesterol. After removal of medium containing the labeled cholesterol, the cells were allowed to equilibrate for $24 \mathrm{~h}$. Subsequently, cholesterol efflux was measured in triplicate over $4 \mathrm{~h}$ in the presence of 20 -fold-diluted plasma samples. Cholesterol efflux (radiolabel present in the culture medium after $4 \mathrm{~h}$ ) is expressed as a percentage of the radioactivity initially present in the cells (fractional efflux). Data were corrected for blanks, being the amount of label in the medium after $4 \mathrm{~h}$ in the absence of plasma. The within-assay coefficient of variation of the cholesterol efflux assay is $5.5 \%$. The fractional cholesterol efflux using Fu5AH cells is mainly attributed to SR-BI, because this cell line has a high expression of SR-BI (27).

\section{Statistical analysis}

Data analysis was performed using the SAS statistical software package (SAS/STAT version 6.12; SAS Institute, Cary, NC). Data were tested for normality using the Shapiro-Wilk test and by visually inspecting normality plots. Treatment effects were evaluated by ANOVA using the mixed-model procedure. The factors treatment, moment, treatment order, BMI, and the interaction term of treatment and BMI were included in the model. The effect of BMI on the outcome measures was obtained from the BMI factor in the ANOVA model. Correlation coefficients to assess the association between (relative changes) outcome measures were calculated according to Pearson or Spearman if variables were not distributed normally. Two-sided probability values were considered statistically significant at $P<0.05$.

\section{RESULTS}

\section{Subjects}

Of the 24 subjects included in the study, 1 subject withdrew from the study at day 21 for a reason not related to treatment. Therefore, only 23 subjects were included in the data analysis of this study. Characteristics of these subjects are shown in Table 1. Average body weight did not differ between the whisky and water treatment periods. The mean breath alcohol concentration at $1 \mathrm{~h}$ after dinner with whisky was $0.43 \mathrm{~g} / \mathrm{l}$ (range, $0.26-0.68 \mathrm{~g} / \mathrm{l}$ ).

\section{Cholesterol efflux capacity}

Treatment effects on the cholesterol efflux capacity of serum or plasma are shown in Table 2. Cholesterol efflux capacity from Fu5AH cells was increased by $4.6 \%(P=$ 
TABLE 1. Characteristics of the volunteers included in the data analysis $(\mathrm{n}=23)$

\begin{tabular}{lc}
\hline Characteristic & Value $^{a}$ \\
\hline Age (years) & $52(5)[45-65]$ \\
Body weight $(\mathrm{kg})$ & $81.4(11.5)[61.2-100.9]$ \\
BMI $\left(\mathrm{kg} / \mathrm{m}^{2}\right)$ & $26.7(3.0)[21.4-33.3]$ \\
Hemoglobin $(\mathrm{mmol} / \mathrm{l})$ & $8.8(0.6)[7.5-10.0]$ \\
TG $(\mathrm{mmol} / \mathrm{l})$ & $1.2(0.7)[0.3-3.0]$ \\
TC $(\mathrm{mmol} / \mathrm{l})$ & $5.6(0.9)[3.9-7.3]$ \\
HDL-C $(\mathrm{mmol} / \mathrm{l})$ & $1.4(0.4)[0.9-2.5]$ \\
LDL-C $(\mathrm{mmol} / \mathrm{l})$ & $3.6(0.7)[2.2-5.5]$ \\
Alkaline phosphatase $(\mathrm{U} / \mathrm{l})$ & $56(13)[39-88]$ \\
Asparagine aminotransferase $(\mathrm{U} / \mathrm{l})$ & $25(5)[18-41]$ \\
Alanine aminotransferase $(\mathrm{U} / \mathrm{l})$ & $28(10)[14-51]$ \\
$\gamma$-Glutamyltransferase $(\mathrm{U} / \mathrm{l})$ & $26(12)[13-49]$ \\
\end{tabular}

BMI, body mass index; HDL-C and LDL-C, HDL and LDL cholesterol; TC, total cholesterol; TG, triacylglycerol.

${ }^{a}$ Data are expressed as means, (SD), and [range].

0.002) after whisky consumption, and cholesterol efflux capacity from J774 cells without stimulation of cAMP also increased after whisky consumption by $3.3 \%(P=0.014)$. After stimulation with cAMP, cholesterol efflux capacity using J774 cells was increased by approximately twice as much $(6.3 \% ; P<0.001)$ after consumption of whisky compared with water. This resulted in a $17.5 \%(P=$ 0.027) increase after consumption of whisky compared with water of the ABCA1-dependent cholesterol efflux in J774 cells. Individual serum ABCA1-dependent cholesterol efflux capacities are shown in Fig. 1.

\section{Blood lipid and lipoprotein profiles and related factors}

Treatment effects on serum lipid profiles and related factors are shown in Table 3. A significant treatment effect on HDL-C was found, indicating a $7.4 \%$ increase of HDL-C after whisky consumption. The HDL-PL fraction increased by $9.3 \%(P<0.0001)$ after whisky consumption compared with water consumption. No treatment effects on TC, LDL-C, VLDL-C, and TG were found (Table 3). Pre $\beta$-HDL increased by $31.6 \%(P=0.026)$, serum apoA-I concentration increased by $6.2 \%(P<0.001)$, and concentration of LpA-I:A-II increased by $6.0 \%(P=0.015)$. A borderline significant $(P=0.069)$ effect of moderate alcohol consumption was observed on LpA-I concentration, suggesting an increase of $6.5 \%$ after whisky consumption compared with water consumption. LCAT activity was increased significantly by $5.8 \%$ after whisky consumption compared with water. No treatment effects were found on CETP and PLTP activity.

\section{BMI effect}

The effect of BMI on cholesterol efflux, lipid and lipoprotein profiles, and related factors is shown in Tables $\mathbf{4}$, 5. Table 4 shows that cholesterol efflux capacities using J774 were higher in lean men $(\mathrm{BMI}<27)$ than in overweight men (BMI $\geqslant 27)$. Also, the cholesterol efflux capacity using Fu5AH cells tended to be lower in overweight men. However, ABCA1-dependent cholesterol efflux capacity was not different between lean and overweight men. Table 5 shows that HDL-C, HDL-PL, apoA-I, and LpA-I were higher in lean men than in overweight men, whereas LCAT activity was $9.2 \%$ higher in overweight men. VLDL-C and TG tended to be lower in lean men than in overweight men. No significant interaction between BMI and alcohol consumption has been found for any of the efflux and lipoprotein variables.

\section{Correlations}

The changes of cAMP-stimulated cholesterol efflux capacity from J774 cells induced by whisky consumption correlated with changes of apoA-I $(r=0.65, P=0.0014)$, HDL-C $(r=0.55, P=0.009)$, HDL-PL $(r=0.56, P=$ $0.008)$, and CETP activity $(r=0.49, P=0.021)$. A borderline significant $(P=0.054)$ correlation $(r=0.42)$ was found between whisky-induced changes in cholesterol efflux capacity using cAMP-treated J774 cells and whiskyinduced changes of cholesterol efflux capacity using Fu5AH cells. Changes of cholesterol efflux capacity from Fu5AH cells correlated $(r=0.52, P=0.012)$ with changes of HDL-PL. Changes of cholesterol efflux capacity from cAMPtreated J774 cells did not correlate significantly with changes of pre $\beta$-HDL $(r=0.30, P=0.18)$. However, whisky-induced changes of pre $\beta$-HDL did correlate with changes in PLTP activity $(r=0.65, P=0.0014)$, apoA-I $(r=0.47, P=$ $0.030)$, and HDL-PL $(r=0.54, P=0.010)$. Changes induced by whisky consumption in serum apoA-I also correlated with changes in HDL-C $(r=0.65, P=0.0015)$, LpAI:A-II $(r=0.61, P=0.0034)$, and HDL-PL $(r=0.66, P=$ $0.0012)$.

\section{DISCUSSION}

In the present study, we investigated the effect of moderate alcohol consumption on cholesterol efflux capacity of serum or plasma by using two different cell systems, providing information on both ABCA1- and SR-BI-mediated cholesterol efflux. We showed an increase of $6.3 \%$ in

TABLE 2. Cholesterol efflux capacities after consumption of whisky or water in 23 healthy middle-aged men

\begin{tabular}{lrrrr}
\hline Efflux & \multicolumn{1}{c}{ Water } & Whisky & Percent Change & \multicolumn{1}{c}{$P^{a}$} \\
\hline Fu5AH cholesterol efflux & $31.69 \pm 0.53$ & $33.15 \pm 0.53$ & 4.6 & 0.002 \\
J774 cholesterol efflux (-cAMP) & $3.37 \pm 0.06$ & $3.48 \pm 0.06$ & 3.3 & 0.014 \\
J774 cholesterol efflux (+cAMP) & $4.16 \pm 0.07$ & $4.42 \pm 0.07$ & 6.3 & $<0.001$ \\
ABCA1-dependent efflux & $0.80 \pm 0.06$ & $0.94 \pm 0.06$ & 17.5 & 0.027 \\
\hline
\end{tabular}

Efflux capacity values are expressed as mean percentages \pm SEM.

${ }^{a}$ ANOVA with treatment, treatment order, period, BMI, and BMI-treatment interaction as fixed factors in the model. 


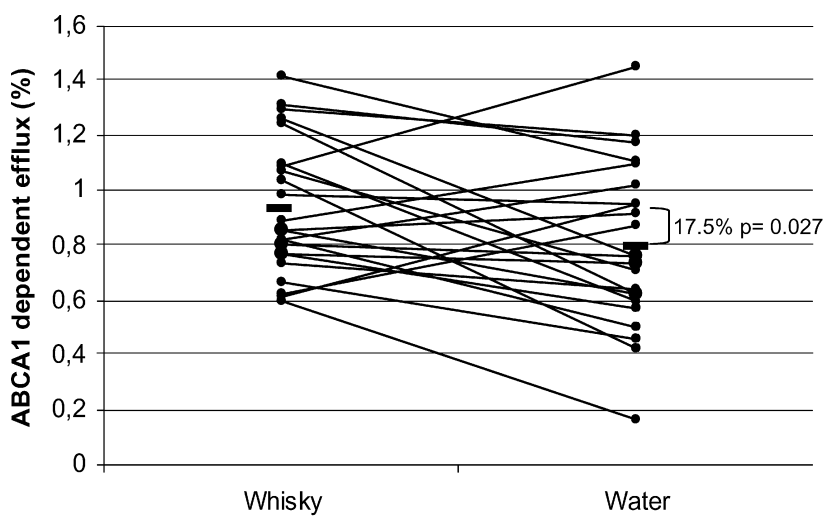

Fig. 1. Individual serum ex vivo ABCA1-dependent cholesterol efflux capacities after consumption of whisky ( $40 \mathrm{~g}$ alcohol/day) or water for 17 days of 23 healthy male subjects.

cAMP-stimulated cholesterol efflux capacity from J774 cells. Consequently, the capacity of serum to induce ABCA1-dependent cholesterol efflux increased by $17.5 \%$. The capacity of plasma to induce cholesterol efflux from Fu5AH cells showed a less pronounced increase of $4.6 \%$. Effects on both cholesterol efflux capacities were associated with concomitant changes of other parameters in the RCT pathway.

The study was partially diet-controlled and performed according to a randomized crossover design. No important deviations from the study protocol occurred, and no significant changes of body weight were found during the study. It is therefore unlikely that the results of this study are confounded by carryover effects or by changes in diet or body weight. In this study, serum and plasma used for the cholesterol efflux experiments were diluted to $1 \%$ to approach the composition of the interstitial fluid that comes in direct contact with the cells. Cholesterol efflux capacities measured in this study were of the same order of magnitude as those described previously $(15,17,28)$. Nevertheless, any extrapolation of the ex vivo cholesterol efflux capacity to the in vivo situation should only be done with caution. However, the consistency between our results of cholesterol efflux capacity and related parameters measured in vivo indicate that in this case this extrapolation is not unreasonable.

The findings of this study, however, do not agree with those of Marmillot et al. (29), who showed a 21\% decrease of cholesterol efflux from mouse J774 macrophages induced by plasma of male Wistar-Furth rats after chronic alcohol consumption. Apart from the species difference, the rats were fed a diet containing as much as $36 \%$ of energy from alcohol, which is much higher than the moderate dose of alcohol $(\sim 10$ energy $\%)$ in our study. This is another reason why the results of these studies cannot be directly compared. A similar inhibition of cholesterol efflux has been reported in a study with in vitro fibroblasts by Avdulov et al. (30) using a high alcohol concentration.

In human intervention studies with moderate alcohol consumption, the effect on cholesterol efflux has only been investigated using Fu5AH hepatoma cells. These studies showed increases in cholesterol efflux of 5-7\% $(15,31)$, which is in accordance with the findings of our current study using this cell system $(4.6 \%)$. The impact of moderate alcohol consumption on cAMP-stimulated (6.3\%) and particularly on ABCA1-dependent cholesterol efflux capacity in J774 cells $(17.5 \%)$ was greater than the effects observed using Fu5AH cells. Our results show that both mechanisms may play a role in the cardioprotective effect of moderate alcohol consumption but suggest that ABCA1-mediated cholesterol efflux may be a more relevant pathway in this respect.

Besides the increased cholesterol efflux capacity, other parameters involved in RCT were also increased by moderate whisky consumption (preß-HDL, HDL-C, HDL-PL, apoA-I, LpA-I, LpA-I:A-II, and LCAT activity). Moreover,

TABLE 3. Blood lipid profiles and related factors after consumption of water or whisky in 23 middle-aged men

\begin{tabular}{|c|c|c|c|c|}
\hline Variable & Water & Whisky & Percent Change & $P^{a}$ \\
\hline $\mathrm{TC}(\mathrm{mmol} / \mathrm{l})$ & $6.01 \pm 0.23$ & $6.02 \pm 0.23$ & 0.2 & 0.94 \\
\hline LDL-C (mmol/l) & $4.28 \pm 0.21$ & $4.14 \pm 0.21$ & -3.3 & 0.30 \\
\hline HDL-C $(\mathrm{mmol} / \mathrm{l})$ & $1.22 \pm 0.05$ & $1.31 \pm 0.05$ & 7.4 & $<0.001$ \\
\hline VLDL-C $(\mathrm{mmol} / \mathrm{l})$ & $0.52 \pm 0.06$ & $0.57 \pm 0.06$ & 9.6 & 0.12 \\
\hline $\mathrm{TG}(\mathrm{mmol} / \mathrm{l})$ & $1.23 \pm 0.15$ & $1.36 \pm 0.15$ & 10.6 & 0.12 \\
\hline HDL-PL (mmol/l) & $1.50 \pm 0.05$ & $1.64 \pm 0.05$ & 9.3 & $<0.0001$ \\
\hline HDL-TG (mmol/l) & $0.12 \pm 0.01$ & $0.13 \pm 0.01$ & 8.3 & 0.20 \\
\hline Pre $\beta$-HDL (mg/ml apoA-I) & $0.038 \pm 0.010$ & $0.050 \pm 0.010$ & 31.6 & 0.026 \\
\hline Total apoA-I (mg/ml) & $1.29 \pm 0.03$ & $1.37 \pm 0.03$ & 6.2 & $<0.001$ \\
\hline LpA-I $(g / 1)$ & $0.46 \pm 0.03$ & $0.49 \pm 0.03$ & 6.5 & 0.069 \\
\hline LpA-I:A-II (g/l) & $0.84 \pm 0.03$ & $0.89 \pm 0.03$ & 6.0 & 0.015 \\
\hline LCAT activity (A.U.) ${ }^{b}$ & $88.95 \pm 2.11$ & $94.14 \pm 2.08$ & 5.8 & 0.007 \\
\hline PLTP activity (A.U.) ${ }^{b}$ & $76.49 \pm 2.76$ & $79.92 \pm 2.73$ & 0.5 & 0.16 \\
\hline CETP activity (A.U.) $^{b}$ & $87.08 \pm 4.91$ & $85.94 \pm 4.90$ & -1.4 & 0.51 \\
\hline
\end{tabular}

Values shown are means \pm SEM. apoA-I, apolipoprotein A-I; CETP, cholesteryl ester transfer protein; LpA-I, lipoprotein A-I; PLTP, phospholipid transfer protein.

${ }^{a}$ ANOVA with treatment, treatment order, period, BMI, and BMI-treatment interaction as fixed factors in the model.

${ }^{b}$ A.U., arbitrary units, corresponding to the percentages of the respective activities in the reference pool plasma; $100 \%$ is equivalent to the following activities: $216 \mathrm{nmol} / \mathrm{ml} / \mathrm{h}$ for CETP, $65 \mathrm{nmol} / \mathrm{ml} / \mathrm{h}$ for LCAT, and $13.9 \mu \mathrm{mol} / \mathrm{ml} / \mathrm{h}$ for PLTP. 
TABLE 4. Cholesterol efflux capacities in 12 lean and 11 overweight middle-aged men

\begin{tabular}{lcccc}
\hline Efflux & \multicolumn{1}{c}{ Lean } & Overweight & Percent Difference & $P^{a}$ \\
\hline Fu5AH cholesterol efflux & $33.33 \pm 0.67$ & $31.53 \pm 0.70$ & -5.7 & 0.076 \\
J774 cholesterol efflux (-cAMP) & $3.56 \pm 0.08$ & $3.29 \pm 0.08$ & -8.2 & 0.028 \\
J774 cholesterol efflux (+cAMP) & $4.45 \pm 0.08$ & $4.13 \pm 0.09$ & -7.7 & 0.018 \\
ABCA1-dependent efflux & $0.89 \pm 0.07$ & $0.85 \pm 0.07$ & -4.7 & 0.68 \\
\hline
\end{tabular}

Efflux capacity values are expressed as mean percentages \pm SEM. model.

${ }^{a}$ ANOVA with treatment, treatment order, period, BMI, and BMI-treatment interaction as fixed factors in the

total apoA-I correlated significantly with cAMP-stimulated cholesterol efflux capacity, which is in agreement with the concept that cholesterol efflux from macrophages may be mediated by cholesterol-poor apoA-I $(32,33)$. On the other hand, the increase of cholesterol efflux capacity did not correlate significantly with changes of pre $\beta$-HDL. This may simply be attributable to the relatively large variance in the cholesterol efflux capacity measure. However, because pre $\beta-H D L$ was measured in vivo and cholesterol efflux was measured ex vivo after $4 \mathrm{~h}$ of incubation, serum proteins involved in the cycle of apoA-I between nascent and mature HDL species such as LCAT, CETP, or PLTP may influence the cholesterol efflux process $(17,34)$. LCAT, which increased significantly after whisky consumption in this study, may contribute to the pre $\beta$-HDL concentration $(17,34)$. On the other hand, additional formation of pre $\beta$-HDL through PLTP may also occur $(35,36)$, as we found a relatively strong correlation $(r=0.65)$ between changes of preß-HDL and PLTP activity in this study. Even using the highly diluted serum, these events could take place during the $4 \mathrm{~h}$ incubation period and may lead to attenuation of the correlation between pre $\beta$ HDL and cholesterol efflux capacity. Finally, the chemical composition of pre $\beta$-HDL may also play a role. This composition is not entirely defined but is likely to contain both precursors and products of ABCA1-mediated choles- terol efflux (34). Thus, because the lipid content of pre $\beta$ HDL may influence the structure and functional properties of apoA-I (37), these variations may affect cholesterol efflux capacity and therefore attenuate its correlation with pre $\beta$-HDL concentration.

We also found significant positive correlations between cholesterol efflux capacity both from J774 and Fu5AH cells and HDL-PL. The latter correlation is in accordance with earlier studies that reported that SR-BI-rich cells are highly sensitive to HDL-PL concentrations $(38,39)$. The correlation between cholesterol efflux capacity from cAMP-treated J774 cells and HDL-PL was also found in patients with primary hypertriglyceridemia by Brites et al. (40). Recent results of Yancey et al. (28) using plasma from human apoA-I transgenic mice, however, are not entirely consistent with these data. This may be attributable to the relatively extreme changes in HDL composition resulting from overexpression in these transgenic mice or to a species difference.

Furthermore, this study shows that cholesterol efflux capacities of serum, HDL-C, HDL-PL, apoA-I, and LpA-I were significantly lower in obese than in lean subjects. VLDL-C and TG tended to be higher and LCAT activity was significantly higher in obese than in lean subjects. Although the differences in our study are less pronounced, our findings show the same pattern as the results of Sasa-

TABLE 5. Blood lipid profiles and related factors in 12 lean and 11 overweight middle-aged men

\begin{tabular}{|c|c|c|c|c|}
\hline Variable & Lean & Overweight & Percent Difference & $P^{a}$ \\
\hline $\mathrm{TC}(\mathrm{mmol} / \mathrm{l})$ & $5.99 \pm 0.29$ & $6.04 \pm 0.30$ & 0.8 & 0.91 \\
\hline LDL-C (mmol/l) & $4.11 \pm 0.27$ & $4.30 \pm 0.28$ & 4.4 & 0.62 \\
\hline HDL-C $(\mathrm{mmol} / \mathrm{l})$ & $1.43 \pm 0.07$ & $1.09 \pm 0.07$ & -31.2 & 0.003 \\
\hline VLDL-C $(\mathrm{mmol} / \mathrm{l})$ & $0.45 \pm 0.08$ & $0.64 \pm 0.08$ & 29.7 & 0.056 \\
\hline $\mathrm{TG}(\mathrm{mmol} / \mathrm{l})$ & $1.06 \pm 0.18$ & $1.53 \pm 0.19$ & 30.7 & 0.056 \\
\hline HDL-PL (mmol/l) & $1.71 \pm 0.06$ & $1.43 \pm 0.06$ & -19.6 & 0.004 \\
\hline HDL-TG $(\mathrm{mmol} / \mathrm{l})$ & $0.12 \pm 0.01$ & $0.13 \pm 0.01$ & 7.7 & 0.49 \\
\hline Pre $\beta$-HDL ( $\mathrm{mg} / \mathrm{ml}$ apoA-I) & $0.043 \pm 0.010$ & $0.045 \pm 0.010$ & 4.4 & 0.65 \\
\hline Total apoA-I $(\mathrm{mg} / \mathrm{ml})$ & $1.44 \pm 0.04$ & $1.23 \pm 0.05$ & -17.1 & 0.004 \\
\hline LpA-I $(\mathrm{g} / \mathrm{l})$ & $0.55 \pm 0.04$ & $0.39 \pm 0.04$ & -41.0 & 0.008 \\
\hline LpA-I:A-II (g/l) & $0.88 \pm 0.03$ & $0.84 \pm 0.04$ & -4.8 & 0.38 \\
\hline LCAT activity (A.U.) $^{b}$ & $87.12 \pm 2.65$ & $95.97 \pm 2.75$ & 9.2 & 0.031 \\
\hline PLTP activity (A.U.) $^{b}$ & $77.83 \pm 3.06$ & $78.58 \pm 3.13$ & 1.0 & 0.84 \\
\hline CETP activity (A.U.) ${ }^{b}$ & $85.91 \pm 6.40$ & $87.11 \pm 6.64$ & 3.8 & 0.89 \\
\hline
\end{tabular}

Values shown are means \pm SEM.

${ }^{a}$ ANOVA with treatment, treatment order, period, BMI, and BMI-treatment interaction as fixed factors in the model.

${ }^{b}$ A.U., arbitrary units, corresponding to the percentages of the respective activities in the reference pool plasma; $100 \%$ is equivalent to the following activities: $216 \mathrm{nmol} / \mathrm{ml} / \mathrm{h}$ for CETP, $65 \mathrm{nmol} / \mathrm{ml} / \mathrm{h}$ for LCAT, and $13.9 \mu \mathrm{mol} / \mathrm{ml} / \mathrm{h}$ for PLTP. 
hara et al. (41), who studied the pathway of cholesterol efflux from human fibroblasts in lean and obese subjects. They found a somewhat larger difference between lean and obese subjects, but this may be attributable to methodological differences, such as another study population or the use of another cell system (fibroblasts). Syvänne et al. (42), using the Fu5AH cell system, observed a decreased cholesterol efflux capacity in patients with noninsulin-dependent diabetes mellitus $(7 \%)$ or coronary artery disease $(7 \%)$ of the same magnitude as our findings in obese subjects.

To the best of our knowledge, this is the first study to show that moderate alcohol consumption increases ABCA1-dependent cholesterol efflux capacity of human serum measured with J774 macrophages. This increase of cholesterol efflux capacity using J774 cells was larger than the increase using Fu5AH cells, suggesting that the ABCA1 transporter is more relevant for the effect of moderate alcohol consumption on HDL-C than the SR-BI. At the same time, moderate alcohol consumption increased other parameters of the RCT pathway, such as total apoA-I, LpA-I:A-II, preß-HDL, HDL-C, and LCAT activity. The increase in serum cholesterol efflux capacity from J774 cells correlated with the increase of total apoA-I, but the correlation with pre $\beta$-HDL did not reach statistical significance. Altogether, these findings suggest that moderate alcohol consumption may stimulate early steps in the RCT pathway mediated by ABCA1. fir

The authors thank the team that conducted this study and the volunteers for their enthusiastic participation. Dr. Pieter H. E. Groot and Leo M. Scheek are thanked for the preparation of the goat anti-human apolipoprotein A-I (apoA-I) antiserum used in the quantitation of pre $\beta$-HDL. Leo M. Scheek also performed the PLTP and LCAT activity assays, and Farah Sadeghi Niaraki measured CETP activities. Cora Groffen measured plasma capacities to induce cholesterol efflux from Fu5AH cells. Dr. Geesje Dallinga-Thie performed the assay of total plasma apoA-I. The research described in this paper was funded by the Dutch Foundation for Alcohol Research.

\section{REFERENCES}

1. Ross, R. 1993. The pathogenesis of atherosclerosis: a perspective for the 1990s. Nature. 362: 801-809.

2. Grobee, D. E., E. B. Rimm, U. Keil, and S. Renaud. 1999. Alcohol and the cardiovascular system. In Health Issues Related to Alcohol Consumption. I. MacDonald, editor. Blackwell Science, Oxford. 125-179.

3. Hendriks, H. F., J. Veenstra, E. J. Velthuis-te Wierik, G. Schaafsma, and C. Kluft. 1994. Effect of moderate dose of alcohol with evening meal on fibrinolytic factors. BMJ. 308: 1003-1006.

4. Pikaar, N. A., M. Wedel, E. J. van der Beek, W. van Dokkum, H. J. Kempen, C. Kluft, T. Ockhuizen, and R. J. Hermus. 1987. Effects of moderate alcohol consumption on platelet aggregation, fibrinolysis, and blood lipids. Metabolism. 36: 538-543.

5. Castelli, W. P., J. T. Doyle, T. Gordon, C. G. Hames, M. C. Hjortland, S. B. Hulley, A. Kagan, and W. J. Zukel. 1977. Alcohol and blood lipids. The cooperative lipoprotein phenotyping study. Lancet. 2: 153-155.

6. Criqui, M. H., L. D. Cowan, H. A. Tyroler, S. Bangdiwala, G. Heiss, R. B. Wallace, and R. Cohn. 1987. Lipoproteins as mediators for the effects of alcohol consumption and cigarette smoking on cardiovascular mortality: results from the Lipid Research Clinics Follow-up Study. Am. J. Epidemiol. 126: 629-637.

7. Hendriks, H. F., J. Veenstra, A. van Tol, J. E. Groener, and G. Schaafsma. 1998. Moderate doses of alcoholic beverages with dinner and postprandial high density lipoprotein composition. Alcohol Alcohol. 33: 403-410.

8. van der Gaag, M. S., A. van Tol, L. M. Scheek, R. W. James, R. Urgert, G. Schaafsma, and H. F. Hendriks. 1999. Daily moderate alcohol consumption increases serum paraoxonase activity: a dietcontrolled, randomised intervention study in middle-aged men. Atherosclerosis. 147: 405-410.

9. van Tol, A., M. S. van der Gaag, L. M. Scheek, T. van Gent, and H. F. Hendriks. 1998. Changes in postprandial lipoproteins of low and high density caused by moderate alcohol consumption with dinner. Atherosclerosis. 141 (Suppl. 1): 101-103.

10. Mackness, B., M. I. Mackness, S. Arrol, W. Turkie, and P. N. Durrington. 1998. Effect of the human serum paraoxonase 55 and 192 genetic polymorphisms on the protection by high density lipoprotein against low density lipoprotein oxidative modification. FEBS Lett. 423: 57-60.

11. Mackness, M. I., S. Arrol, B. Mackness, and P. N. Durrington. 1997. Alloenzymes of paraoxonase and effectiveness of high-density lipoproteins in protecting low-density lipoprotein against lipid peroxidation. Lancet. 349: 851-852.

12. Fielding, C. J., and P. E. Fielding. 1995. Molecular physiology of reverse cholesterol transport. J. Lipid Res. 36: 211-228.

13. Owen, J. S., and J. V. Mulcahy. 2002. ATP-binding cassette A1 protein and HDL homeostasis. Atheroscler. Suppl. 3: 13-22.

14. Rothblat, G. H., M. Llera-Moya, V. Atger, G. Kellner-Weibel, D. L. Williams, and M. C. Phillips. 1999. Cell cholesterol efflux: integration of old and new observations provides new insights. J. Lipid Res. 40: 781-796.

15. van der Gaag, M. S., A. van Tol, S. H. Vermunt, L. M. Scheek, G. Schaafsma, and H. F. Hendriks. 2001. Alcohol consumption stimulates early steps in reverse cholesterol transport. J. Lipid Res. 42: 2077-2083.

16. Singaraja, R. R., C. Fievet, G. Castro, E. R. James, N. Hennuyer, S. M. Clee, N. Bissada, J. C. Choy, J. C. Fruchart, B. M. McManus, B. Staels, and M. R. Hayden. 2002. Increased ABCA1 activity protects against atherosclerosis. J. Clin. Invest. 110: 35-42.

17. Fournier, N., O. Francone, G. Rothblat, D. Goudouneche, M. Cambillau, G. Kellner-Weibel, P. Robinet, L. Royer, N. Moatti, A. Simon, and J. L. Paul. 2003. Enhanced efflux of cholesterol from ABCA1-expressing macrophages to serum from type IV hypertriglyceridemic subjects. Atherosclerosis. 171: 287-293.

18. Friedewald, W. T., R. I. Levy, and D. S. Fredrickson. 1972. Estimation of the concentration of low-density lipoprotein cholesterol in plasma, without use of the preparative ultracentrifuge. Clin. Chem. 18: 499-502.

19. Groener, J. E., R. W. Pelton, and G. M. Kostner. 1986. Improved estimation of cholesteryl ester transfer/exchange activity in serum or plasma. Clin. Chem. 32: 283-286.

20. Speijer, H., J. E. Groener, E. van Ramshorst, and A. van Tol. 1991. Different locations of cholesteryl ester transfer protein and phospholipid transfer protein activities in plasma. Atherosclerosis. 90: 159-168.

21. van Venrooij, F. V., R. P. Stolk, J. D. Banga, T. P. Sijmonsma, A. van Tol, D. W. Erkelens, and G. M. Dallinga-Thie. 2003. Common cholesteryl ester transfer protein gene polymorphisms and the effect of atorvastatin therapy in type 2 diabetes. Diabetes Care. 26: 12161223.

22. Joles, J. A., N. Willekes-Koolschijn, L. M. Scheek, H. A. Koomans, T. J. Rabelink, and A. van Tol. 1994. Lipoprotein phospholipid composition and LCAT activity in nephrotic and analbuminemic rats. Kidney Int. 46: 97-104.

23. Fournier, N., V. Atger, J. L. Paul, M. Sturm, N. Duverger, G. H. Rothblat, and N. Moatti. 2000. Human apoA-IV overexpression in transgenic mice induces cAMP-stimulated cholesterol efflux from J774 macrophages to whole serum. Arterioscler. Thromb. Vasc. Biol. 20: $1283-1292$.

24. Fournier, N., A. Cogny, V. Atger, D. Pastier, D. Goudouneche, A. Nicoletti, N. Moatti, J. Chambaz, J. L. Paul, and A. D. Kalopissis. 2002. Opposite effects of plasma from human apolipoprotein A-II transgenic mice on cholesterol efflux from J774 macrophages and Fu5AH hepatoma cells. Arterioscler. Thromb. Vasc. Biol. 22: 638-643.

25. Sakr, S. W., D. L. Williams, G. W. Stoudt, M. C. Phillips, and G. H. 
Rothblat. 1999. Induction of cellular cholesterol efflux to lipidfree apolipoprotein A-I by cAMP. Biochim. Biophys. Acta. 1438: 8598.

26. de la Llera Moya, M. M., V. Atger, J. L. Paul, N. Fournier, N. Moatti, P. Giral, K. E. Friday, and G. Rothblat. 1994. A cell culture system for screening human serum for ability to promote cellular cholesterol efflux. Relations between serum components and efflux, esterification, and transfer. Arterioscler. Thromb. 14: 1056-1065.

27. Ji, Y., B. Jian, N. Wang, Y. Sun, M. L. Moya, M. C. Phillips, G. H. Rothblat, J. B. Swaney, and A. R. Tall. 1997. Scavenger receptor BI promotes high density lipoprotein-mediated cellular cholesterol efflux. J. Biol. Chem. 272: 20982-20985.

28. Yancey, P. G., M. A. Kawashiri, R. Moore, J. M. Glick, D. L. Williams, M. A. Connelly, D. J. Rader, and G. H. Rothblat. 2004. In vivo modulation of HDL phospholipid has opposing effects on SRBI- and ABCA1-mediated cholesterol efflux. J. Lipid Res. 45: 337346.

29. Marmillot, P., M. N. Rao, Q. H. Liu, S. J. Chirtel, and M. R. Lakshman. 2000. Effect of dietary omega-3 fatty acids and chronic ethanol consumption on reverse cholesterol transport in rats. Metabolism. 49: 508-512.

30. Avdulov, N. A., S. V. Chochina, U. Igbavboa, and W. G. Wood. 2000. Cholesterol efflux to high-density lipoproteins and apolipoprotein A-I phosphatidylcholine complexes is inhibited by ethanol: role of apolipoprotein structure and cooperative interaction of phosphatidylcholine and cholesterol. Biochemistry. 39: 1059910606.

31. Senault, C., D. Betoulle, G. Luc, P. Hauw, D. Rigaud, and F. Fumeron. 2000. Beneficial effects of a moderate consumption of red wine on cellular cholesterol efflux in young men. Nutr. Metab. Cardiovasc. Dis. 10: 63-69.

32. Hara, H., and S. Yokoyama. 1991. Interaction of free apolipoproteins with macrophages. Formation of high density lipoproteinlike lipoproteins and reduction of cellular cholesterol. J. Biol. Chem. 266: 3080-3086.

33. Yancey, P. G., J. K. Bielicki, W. J. Johnson, S. Lund-Katz, M. N. Palgunachari, G. M. Anantharamaiah, J. P. Segrest, M. C. Phillips, and G. H. Rothblat. 1995. Efflux of cellular cholesterol and phospholipid to lipid-free apolipoproteins and class A amphipathic peptides. Biochemistry. 34: 7955-7965.
34. Barrans, A., B. Jaspard, R. Barbaras, H. Chap, B. Perret, and X. Collet. 1996. Pre-beta HDL: structure and metabolism. Biochim. Biophys. Acta. 1300: 73-85.

35. Lie, J., R. de Crom, M. Jauhiainen, T. van Gent, R. van Haperen, L. Scheek, H. Jansen, C. Ehnholm, and A. van Tol. 2001. Evaluation of phospholipid transfer protein and cholesteryl ester transfer protein as contributors to the generation of pre beta-high-density lipoproteins. Biochem. J. 360: 379-385.

36. Pussinen, P. J., M. Jauhiainen, and C. Ehnholm. 1997. ApoA-II/ apoA-I molar ratio in the HDL particle influences phospholipid transfer protein-mediated HDL interconversion. J. Lipid Res. 38: $12-21$.

37. Sparks, D. L., P. G. Frank, S. Braschi, T. A. Neville, and Y. L. Marcel. 1999. Effect of apolipoprotein A-I lipidation on the formation and function of pre-beta and alpha-migrating LpA-I particles. Biochemistry. 38: 1727-1735.

38. Atger, V., M. M. de la Llera, M. Bamberger, O. Francone, P. Cosgrove, A. Tall, A. Walsh, N. Moatti, and G. Rothblat. 1995. Cholesterol efflux potential of sera from mice expressing human cholesteryl ester transfer protein and/or human apolipoprotein A-I. $J$. Clin. Invest. 96: 2613-2622.

39. Fournier, N., M. M. de la Llera, B. F. Burkey, J. B. Swaney, J. Paterniti, Jr., N. Moatti, V. Atger, and G. H. Rothblat. 1996. Role of HDL phospholipid in efflux of cell cholesterol to whole serum: studies with human apoA-I transgenic rats. J. Lipid Res. 37: 1704-1711.

40. Brites, F. D., C. D. Bonavita, C. De Geitere, M. Cloes, B. Delfly, M. J. Yael, J. Fruchart, R. W. Wikinski, and G. R. Castro. 2000. Alterations in the main steps of reverse cholesterol transport in male patients with primary hypertriglyceridemia and low HDL-cholesterol levels. Atherosclerosis. 152: 181-192.

41. Sasahara, T., P. Nestel, N. Fidge, and D. Sviridov. 1998. Cholesterol transport between cells and high density lipoprotein subfractions from obese and lean subjects. J. Lipid Res. 39: 544-554.

42. Syvänne, M., G. Castro, C. Dengremont, C. De Geitere, M. Jauhiainen, C. Ehnholm, S. Michelagnoli, G. Franceschini, J. Kahri, and M. R. Taskinen. 1996. Cholesterol efflux from Fu5AH hepatoma cells induced by plasma of subjects with or without coronary artery disease and non-insulin-dependent diabetes: importance of LpA-I: A-II particles and phospholipid transfer protein. Atherosclerosis. 127: 245-253. 